Table 1. Mean (SD) outcome scores by treatment type

\begin{tabular}{lccc}
\hline & $\begin{array}{c}\text { Advanced } \\
\text { therapies } \\
\mathbf{N}=\mathbf{6 5}\end{array}$ & $\begin{array}{c}\text { Other } \\
\text { therapies } \\
\mathbf{N}=\mathbf{2 7 4}\end{array}$ & $\begin{array}{c}\text { Not treated } \\
\mathbf{N}=\mathbf{6 0 8}\end{array}$ \\
\hline SF-36 MCS & $38.0(11.0)$ & $40.1(11.6)$ & $39.8(10.5)$ \\
SF-36 PCS & $36.0(9.9)$ & $37.6(9.6)$ & $43.9(8.4)$ \\
\hline PHQ-9 total score ${ }^{\mathrm{a}}$ & $7.7(7.0)$ & $9.1(6.8)$ & $7.8(7.1)$ \\
\hline $\begin{array}{l}\text { WPAI domain scores } \\
\text { \% work missed }\end{array}$ & $26.8(29.7)$ & $27.8(35.4)$ & $20.8(27.8)$ \\
$\quad$ \% impairment at work & $55.8(31.1)$ & $42.8(29.6)$ & $44.5(29.3)$ \\
$\quad$ \% overall work impairment & $61.4(34.2)$ & $49.0(33.2)$ & $51.1(32.6)$ \\
$\quad$ \% activity impairment & $62.0(26.1)$ & $57.8(26.5)$ & $48.3(28.9)$ \\
\hline${ }^{\mathrm{a}} \mathrm{N}=22,45,137$ for advanced therapies, other therapies, not treated, respectively
\end{tabular}

${ }^{a} \mathrm{~N}=22,45,137$ for advanced therapies, other therapies, not treated, respectively

${ }^{b} \mathrm{~N}$ for WPAI $\%$ work missed $=33,113,338$, respectively for advanced therapies, other therapies, not treated; $\mathrm{N}$ for WPAI \% impairment at work and overall work

impairment $=33,99,328$, respectively, for advanced therapies, other therapies and not treated

MCS, mental component summary; PCS, physical component summary; PHQ-9, Patient Health Questionnaire-9; SD, standard deviation; SF-36, Short Form-36 health survey; WPAI, Work Productivity and Activity Impairment questionnaire

treatment. Regardless of treatment group, pts reported $>20 \%$ work loss and $>45 \%$ work impairment. Among treated pts, $>50 \%$ reported moderate or severe PsA, suggesting a need for overall better management of PsA to reduce the disease impact and improve quality of life. Our results are limited by self-reported PsA diagnosis, which may differ from physician-reported PsA diagnosis, and the survey being conducted in the EU only, which may differ from other parts of the world. Further statistical analyses are needed to determine differences between groups and correlation to other health indicators.

Acknowledgements: This study was sponsored by Pfizer Inc. Editorial support was provided by A Pedder of CMC and was funded by Pfizer Inc.

Disclosure of Interest: A. Gottlieb Grant/research support from: Abbott (AbbVie), Amgen, Baxalta, Celgene, Centocor (Janssen), Coronado, Dermira, Eli Lilly, Levia, Merck, Novartis, Pfizer Inc, Xenoport, Consultant for: Abbott (AbbVie), Actelion, Akros, Amgen, Astellas, Baxalta, Beiersdorf, Bristol-Myers Squibb, Canfite, Catabasis, Celgene, Centocor (Janssen), Coronado, CSL Behring Biotherapies for Life, Dermipsor, Eli Lilly, Genentech, GlaxoSmithKline, Incyte, Karyopharm, Meiji Seika Pharma, Mitsubishi Tanabe, Novo Nordisk, Novartis, Pfizer Inc, Takeda, TEVA, UCB, Vertex, Xenoport, J. Gratacos: None declared, A. Dikranian Consultant for: AbbVie, Mallinckrodt, Pfizer Inc, Speakers bureau: AbbVie, Amgen, Celgene, Mallinckrodt, Pfizer Inc, L. Fallon Shareholder of: Pfizer Inc, Employee of: Pfizer Inc, B. Emir Shareholder of: Pfizer Inc, Employee of: Pfizer Inc, T. Smith Shareholder of: Pfizer Inc, Employee of: Pfizer Inc, L. Aikman Shareholder of: Pfizer Inc, Employee of: Pfizer Inc, L. Chen Shareholder of: Pfizer Inc, Employee of: Pfizer Inc

DOI: 10.1136/annrheumdis-2017-eular.2446

\section{FRI0485 IN PERIPHERAL PSORIATIC ARTHRITIS DKK-1 AND PTH ARE LOWER THAN IN RHEUMATOID ARTHRITIS AND HEALTHY CONTROLS}

A. Fassio, L. Idolazzi, O. Viapiana, C. Benini, E. Vantaggiato, M. Rossini, D. Gatti. Rheumatology, Aoui Verona Reumatologia, Verona, Italy

Background: The recent characterization of the canonical WNT pathway in the regulation of bone modeling and remodeling provided important insights for our understanding of the pathophysiology of bone involvement in chronic arthritis [1]. Dkk-1 and sclerostin are the main regulators of WNT/b-catenin signaling, regulating both bone formation and resorption [2]. In a previous our study we showed that in patients with Rheumatoid Arthritis (RA) Dkk-1 is significantly increased and associated with the presence of typical erosions and lower BMD [3].

Objectives: we decided to perform this study in order to compare the serum levels of WNT-pathway regulators alongside bone turnover markers (BTM) and Parathyroid Hormone (PTH) between a group of female patients with PsA and healthy controls $(\mathrm{HC})$ or patients with Rheumatoid Arthritis (RA).

Methods: this is a cross-sectional study including 18 patients with PsA classified with the CASPAR criteria, $35 \mathrm{HC}$, and 28 patients with RA classified with the ACR/EULAR 2010 criteria. Intact N-propeptide of type I collagen (PINP), Cterminal telopeptide of type I collagen (CTX-I), Dickkopf-related-protein 1 (Dkk-1), sclerostin, PTH and $25 \mathrm{OH}$-Vitamin D serum levels were dosed. All procedures performed in studies involving human participants were in accordance with the ethical standards of the institutional and/or national research committee and with the 1964 Helsinki declaration and its later amendments or comparable ethical standards. Informed consent was obtained from all individual participants included in the study.
Results: the PsA group showed significantly lower Dkk-1 levels when compared to the $\mathrm{HC}$ and RA groups. Dkk-1 in the RA group was also significantly higher than in the $\mathrm{HC}$ group. A similar trend was documented also for $\mathrm{PTH}$, however a statistically significant difference was observed only when we comparing the PsA vs RA group (table 1, figure 1). No other statistically significant differences in the other markers were found.

Table 1. Values of bone turnover markers (CTX-I, PINP), Dkk-1 and sclerostin of PsA, RA patients and control group (mean $\pm \mathrm{SD}$ )

\begin{tabular}{lcccc}
\hline & PsA & RA & HC & P (ANOVA) \\
\hline PINP ng/ml & $42,80 \pm 16,670$ & $39,19 \pm 21,38$ & $42,49 \pm 11,52$ & NS \\
CTX-I ng/ml & $0,21 \pm 0,17$ & $0,32 \pm 0,21$ & $0,28 \pm 0,10$ & NS \\
Dkk- $1 \mathrm{pmol} / \mathrm{I}$ & $19,45 \pm 11,30$ & $44,51 \pm 17,81$ & $27,29 \pm 11,48$ & $<0,001$ \\
Sclerostin pmol/l & $30,82 \pm 11,25$ & $30,75 \pm 10,25$ & $34,23 \pm 17,29$ & NS \\
PTH pg/ml & $21,12 \pm 16,63$ & $35,83 \pm 13,02$ & $29,69 \pm 11,43$ & $<0,005$ \\
\hline
\end{tabular}
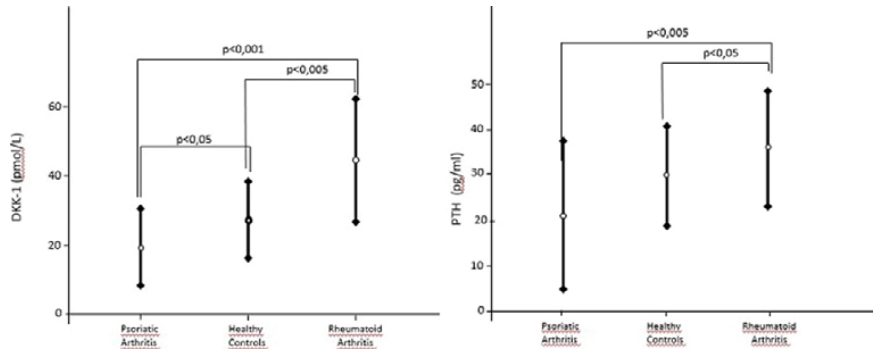

Conclusions: this study demonstrated for the first time that Dkk-1 levels in PsA are lower than $\mathrm{HC}$, in contrast with RA where they are higher. These results might contribute to explain the different bone involvement of the two different diseases. References:

[1] Xie W, Zhou L, Li S, et al. Wnt/ $\beta$-catenin signaling plays a key role in the development of spondyloarthritis. Ann N Y Acad Sci 2016;1364:25-31. doi:10.1111/nyas. 12968 .

[2] 2 Spencer GJ, Utting JC, Etheridge SL, et al. Wnt signalling in osteoblasts regulates expression of the receptor activator of NFkappaB ligand and inhibits osteoclastogenesis in vitro. J Cell Sci 2006;119:1283-96. doi:10.1242/jcs.02883.

[3] 3 Rossini M, Viapiana O, Adami S, et al. In patients with rheumatoid arthritis, Dickkopf-1 serum levels are correlated with parathyroid hormone, bone erosions and bone mineral density. Clin Exp Rheumatol 2015;33:77-83.

Disclosure of Interest: None declared

DOI: 10.1136/annrheumdis-2017-eular.2728

\section{FRI0486 INTRAVENOUS GOLIMUMAB IN ADULT PATIENTS WITH ACTIVE PSORIATIC ARTHRITIS: EFFICACY AND SAFETY THROUGH WEEK 24}

A. Kavanaugh ${ }^{1}$, M.E. Husni ${ }^{2}$, D.D. Harrison ${ }^{3}$, L. Kim ${ }^{3}$, K.H. Lo ${ }^{3}$, E.C. Hsia ${ }^{4}$. ${ }^{1}$ University of California, San Diego; ${ }^{2}$ Cleveland Clinic, Cleveland; ${ }^{3}$ Janssen Research \& Development, LLC, Spring House; ${ }^{4}$ Janssen Research \& Development, LLC/University of Pennsylvania School of Medicine, Spring House/Philadelphia, United States

Objectives: The GO-VIBRANT study was designed to evaluate the safety and efficacy of intravenous (IV) golimumab (GLM) in adult patients (pts) with active PsA (biologic-naïve).

Methods: GO-VIBRANT is a Phase 3, multicenter, randomized, double-blind, placebo (PBO)-controlled trial. Biologic-naïve active PsA pts were randomized $(1: 1)$ to IV GLM $2 \mathrm{mg} / \mathrm{kg}$ at weeks (wk) 0,4 , and every 8 wks thereafter or PBO at wks $0,4,12$, and 20 with crossover to GLM at wk24. The primary endpoint was ACR20 response at wk14. Multiplicity-controlled endpoints were ACR50, ACR70, PASI 75, change from baseline in HAQ-DI, enthesitis, dactylitis, SF-36 PCS/MCS scores at wk14; and ACR50 and change from baseline in total modified vdH-S (structural damage) score at wk24. Efficacy analyses were based on randomized treatment. Adverse events (AE) through wk24 are reported here. Investigators remain blinded through wk60.

Results: 480 pts were randomized (PBO: 239; GLM: 241). The study met its primary and all controlled secondary endpoints. At wk14, significantly greater proportions of GLM pts vs PBO achieved ACR20 (75.1\% vs. $21.8 \%$ ). Also, GLM treatment resulted in significant change from baseline HAQ-DI score $(-0.60$ vs. -0.12 ), ACR50 (43.6\% vs. $6.3 \%$ ), PASI 75 (59.2\% vs. $13.6 \%$ ), ACR70 (24.5\% vs. $2.1 \%)$, change from baseline in enthesitis and dactylitis scores (-1.8 vs. -0.8 and -7.8 vs. -2.8 , respectively), and change from baseline in SF-36 PCS and SF-36 MCS scores (8.65 vs. 2.69 and 5.33 vs. 0.97 , respectively) (all $p<0.001$ ) at wk14. At wk24, significantly greater proportions of GLM pts vs. PBO pts achieved ACR $50(53.5 \%$ vs. $6.3 \%, p<0.001)$. At wk24, there was significantly less progression of structural damage for GLM pts vs PBO as measured by change from baseline in total modified vdH-S score ( -0.36 vs. $1.95 ; p<0.001)$. ACR20 was significantly higher with GLM than PBO as early as wk2 (45.6\% vs. $7.5 \% ; p<0.001) .27 .0 \%$ of GLM pts (vs. 4.2\% PBO) achieved Minimal Disease Activity by wk14. Due to the difference in response rates in GLM vs. PBO treated pts, the number needed to treat for ACR20 at wk14 was 1.9 in a post-hoc analysis (Table). Through wk24, 
$46.3 \%$ of GLM pts and $40.6 \%$ of PBO pts had $>1 \mathrm{AE} ; 2.9 \%$ vs. $3.3 \%$ of pts, respectively, had $\geq 1$ serious $A E$. Two deaths, 2 malignancies, and 1 demyelinating event were reported. The most common treatment-emergent type of AE was infection $(20.0 \%$ of GLM pts vs. $13.8 \%$ of PBO pts). No opportunistic infection or tuberculosis was reported through wk24. The rate of infusion reactions was low at $<2 \%$; none was serious or severe.

\begin{tabular}{|c|c|c|c|}
\hline & Placebo & Golimumab $2 \mathrm{mg} / \mathrm{kg}$ & P-values \\
\hline Patients randomized, $\mathrm{n}$ & 239 & 241 & \\
\hline \multicolumn{4}{|l|}{ Clinical efficacr at wk14 } \\
\hline ACR20/50/70, (\%) & $21.8 / 6.3 / 2.1$ & $75.1 / 43.6 / 24.5$ & $p<0.001$ \\
\hline PASI $75, \mathrm{n}(\%)^{*}$ & $27 / 198(13.6 \%)$ & $116 / 196(59.2 \%)$ & $p<0.001$ \\
\hline Change from $\mathrm{BL}$ in HAQ-DI (n) & 222 & 233 & \\
\hline Mean (SD) & $-0.12(0.47)$ & $-0.60(0.53)$ & $p<0.001$ \\
\hline Change from BL in enthesitis** (n) & 173 & 182 & \\
\hline $\operatorname{Mean}(\mathrm{SD})$ & $-0.8(1.98)$ & $-1.87(1.75)$ & $p<0.001$ \\
\hline Change from $\mathrm{BL}$ in dactylitis** (n) & 115 & 130 & \\
\hline Mean (SD) & $-2.8(7.03)$ & $-7.8(8.57)$ & $p<0.001$ \\
\hline Minimal Disease Activity, $\mathrm{n} N(\%)$ & $10 / 239(4.2 \%)$ & $65 / 241(27.0 \%)$ & $\mathrm{p}<0.001$ \\
\hline Number Needed to Treat $(95 \% \mathrm{CI})$ & & $1.9(1.64,2.18)$ & \\
\hline \multicolumn{4}{|l|}{ Clinical efficacy at Week 24} \\
\hline ACR $50, n(\%)$ & $15(6.3 \%)$ & $129(53.5 \%)$ & \\
\hline \multicolumn{4}{|l|}{ Imaging data at Week 24} \\
\hline Change from $\mathrm{BL}$ in vdH-S score $\mathrm{C}$ & 237 & 237 & \\
\hline \multicolumn{4}{|l|}{ HRQoL at wk14 } \\
\hline Change from BL in SF-36 PCS score & 222 & 233 & \\
\hline & $\frac{69(5.92)}{202}$ & $\frac{8.65(7.60)}{233}$ & $p<0.001$ \\
\hline $\begin{array}{r}\text { Change from BL in SF-36 MCS score (n) } \\
\text { Mean (SD) }\end{array}$ & $\begin{array}{ll}222 \\
0.97(7.64)\end{array}$ & $\begin{array}{c}233 \\
5.33(9.95)\end{array}$ & $\mathrm{p}<0.001$ \\
\hline
\end{tabular}

Conclusions: In pts with active PsA, IV GLM demonstrated significant and clinically meaningful improvements of disease activity and physical function, skin psoriasis clearance, $\mathrm{HRQ}$ oL, reduction in dactylitis and enthesitis, and inhibition of structural damage progression. GLM was well-tolerated through wk24; the safety profile was consistent with other anti-TNF therapies, including SC GLM.

Disclosure of Interest: A. Kavanaugh Consultant for: Janssen, M. E. Husni Consultant for: Janssen, UCB, Amgen, Novartis, Lilly, Regeneron, D. Harrison Employee of: Janssen Research \& Development, LLC, L. Kim Employee of: Janssen Research \& Development, LLC, K. H. Lo Employee of: Janssen Research \& Development, LLC, E. Hsia Employee of: Janssen Research \& Development, LLC

DOI: 10.1136/annrheumdis-2017-eular.1165

\section{FRI0487 APREMILAST IS ASSOCIATED WITH LONG-TERM (4-YEAR) DAS-28 (CRP) REMISSION AND IMPROVEMENTS IN SKIN DISEASE: RESULTS FROM A PHASE III STUDY IN DMARD/BIOLOGIC-EXPERIENCED PATIENTS WITH ACTIVE PSORIATIC ARTHRITIS}

C.J. Edwards ${ }^{1}$, F.J. Blanco ${ }^{2}$, J. Crowley ${ }^{3}$, M. Mcllraith ${ }^{4}$, M. Paris ${ }^{4}$, N. Delev ${ }^{4}$ L. Teng ${ }^{4}$, C.A. Birbara ${ }^{5} .{ }^{1}$ University Hospital Southampton, Southampton, United Kingdom; ${ }^{2}$ INIBIC-Hospital Universitario A Coruña, Galicia, Spain; ${ }^{3}$ Bakersfield Dermatology, Bakersfield; ${ }^{4}$ Celgene Corporation, Summit;

${ }^{5}$ University of Massachusetts Medical School, Worcester, United States

Background: Treatment goals for long-term control of skin and joint symptoms in active psoriatic arthritis (PsA) include clinically important changes in DAS-28 (CRP), achievement of remission in DAS-28 (CRP), reduction in swollen joint count (SJC), and decrease in skin disease. ${ }^{1}$ PALACE 3 included PsA patients with active joint disease and an active skin lesion at the time of enrollment.

Objectives: Report the impact of apremilast (APR) on PsA manifestations over 4 years.

Methods: Patients were stratified by baseline (BL) DMARD use (yes/no) and psoriasis involvement of the body surface area $(<3 \% />3 \%)$ and randomized (1:1:1) to placebo (PBO), APR $30 \mathrm{mg}$ BID (APR30), or APR $20 \mathrm{mg}$ BID (APR20). After the 24-week PBO-controlled phase, all patients were treated with APR30 or APR20 and could enroll in the long-term extension. Efficacy assessments were conducted through Week 208.

Results: 505 patients were randomized and received $>1$ dose of study medication (PBO: $n=169$; APR30: $n=167$; APR20: $n=169$ ). A total of $91 \%$ (227/249) of patients starting the fourth year of APR therapy completed the Week 208 visit. Patients treated with APR30 demonstrated sustained decreases in disease activity at Week 208, as shown by mean change from BL in DAS-28 (CRP) of $-1.66 ; 80.3 \%$ achieved good/moderate EULAR response and $50.4 \%$ achieved DAS-28 (CRP) remission. Sustained effect on inflammation at Week 208 was also demonstrated by mean/median percent changes in SJC, a marker of inflammatory activity, of $-77.4 \% /-100.0 \%$ (Table); $64.8 \%$ of patients had an SJC of 0 or 1 . Decreases in disability and maintenance of functionality were shown by sustained improvements in Health Assessment Questionnaire-Disability Index (HAQ-DI) scores (Table). A continued effect on skin disease was shown by decreases in skin involvement, as measured by the Psoriasis Area and Severity Index (PASI); $54.7 \%$ of APR30 patients had BL PASI $>5$ and $27.3 \%$ had BL PASI $>10$; at Week 208, 64.5\% had PASI $<3$ and $77.4 \%$ had PASI $\leq 5$. PASI-75 and PASI-50 response rates also demonstrated clinically significant relief (Table). In patients treated with APR20, similar findings were observed at Week 208. No new safety concerns were identified through 208 weeks of APR30 therapy. During Weeks $>156$ to $\leq 208$ of APR30 exposure, the only adverse event (AE) occurring in $>5 \%$ of patients was nasopharyngitis; most AEs were mild or moderate in severity. Serious AEs occurred in $7.2 \%$ of APR30 patients over Weeks $>156$ to $\leq 208$, similar to rates in earlier study periods. Few discontinuations due to AEs $(0.7 \%)$ occurred over Weeks $>156$ to $\leq 208$. The APR20 safety profile was similar to that of APR30.

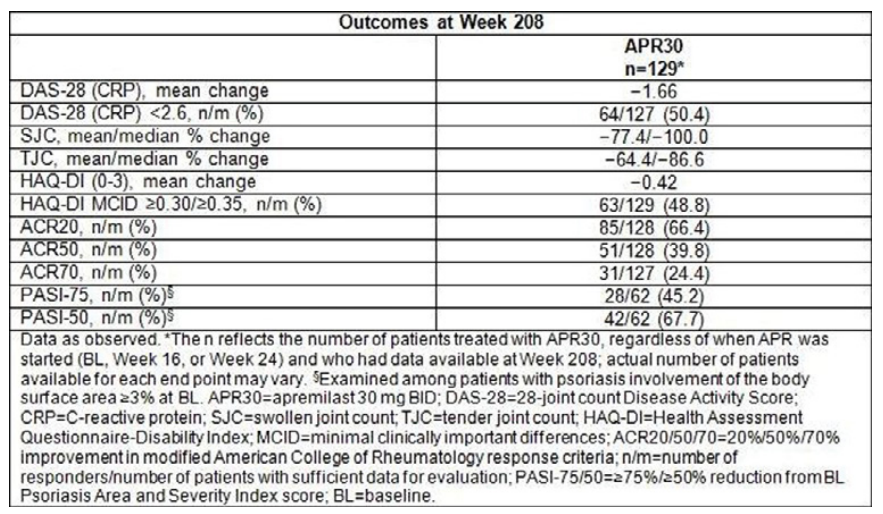

Conclusions: Over 208 weeks, APR demonstrated sustained and clinically important improvements in PsA signs and symptoms, including physical function and associated psoriasis, among patients continuing the study. APR was generally well tolerated with an acceptable safety profile.

References:

[1] Gossec L, et al. Ann Rheum Dis. 2016:75:499-510.

Disclosure of Interest: C. Edwards Grant/research support from: Celgene Corporation, Pfizer, Roche, Samsung, Consultant for: Celgene Corporation, Pfizer, Roche, Samsung, Speakers bureau: Abbott, GSK, Pfizer, Roche, F. Blanco Consultant for: Bioibérica, Gebro Pharma, Pfizer, J. Crowley Grant/research support from: AbbVie, Amgen, Celgene Corporation, Janssen, Merck, Pfizer, Consultant for: AbbVie, Amgen, Speakers bureau: AbbVie, M. Mcllraith Employee of: Celgene Corporation, M. Paris Employee of: Celgene Corporation, N. Delev Employee of: Celgene Corporation, L. Teng Employee of: Celgene Corporation, C. Birbara Grant/research support from: Amgen, BMS, Incyte, Eli Lilly, Merck, Pfizer

DOI: 10.1136/annrheumdis-2017-eular.3563

\section{FRI0488 PSORIATIC ARTHRITIS IN THE UNITED STATES: INCREASING ALL-CAUSE HOSPITALIZATIONS 1993-2014}

G. Singh ${ }^{1}$, C. Moise $^{2}$, A. Mithal ${ }^{3}$, R. lonescu ${ }^{2}$, A. Mithal ${ }^{4} .{ }^{1}$ Gastroenterology and Hepatology, Stanford University, Palo Alto, United States; ${ }^{2}$ Disciplina

Medicina Interna si Reumatologie, Spitalul Clinic "Sf. Maria", Bucharest,

Romania; ${ }^{3}$ Student; ${ }^{4}$ Epidemiology, ICORE, Woodside, United States

Background: Psoriatic arthritis (PsA) is a rare disease, with an estimated prevalence of $0.02-0.42 \%$ in Europe and US (1). PsA is often regarded as a mild disease, but recent data suggest an increase in comorbidities and mortality, possibly related to systemic inflammation (1).

Objectives: To study all-cause hospitalizations in patients with PsA in the United States (US) from 1993 to 2014.

Methods: The Nationwide Inpatient Sample (NIS) is a stratified random sample of all US community hospitals. It is the only US national hospital database with information on all patients, regardless of payer, including persons covered by Medicare, Medicaid, private insurance, and the uninsured. We examined all inpatient hospitalizations in NIS from 1993 to 2014 with a primary or secondary diagnosis of PsA, and compared them to total all-cause US hospitalizations during the same period. US population estimates and projections for the resident US population were obtained from the US Census Bureau.

Results: There were 789.8 million all-cause hospitalizations in 6.4 billion personyears of observation from 1993 to 2014 (123.4 hospitalizations per 1,000 person-years). During this time-period, 332,496 hospitalizations occurred in patients with PsA (5.2 per 100,000 person-years). All-cause US hospitalizations increased from 33.7 million in 1993 to 35.4 million in 2014, an increase of $4.8 \%$ over 22 years (Figure, dotted blue line). All-cause hospitalizations in PsA patients have increased from 6,866 in 1993 (2.6 per 100,000 person-year) to 33,875 in 2014 (10.6 per 100,000 person-years, a dramatic increase of over $393 \%$ ( $p<0.0001$, Figure solid red line). In 2014, hospitalizations in PsA patients accounted for 163,630 hospital days at a total national cost of over US $\$ 1.66$ billion.

Conclusions: All-cause hospitalizations in patients with PSA in the US have significantly increased by $393 \%$ in the last 22 years, almost 80 -fold of the $4.8 \%$ increase in US population all-cause hospitalization rate in the same time-period. This calls for an increase need for identification and management of serious co-morbid conditions in patients with PsA. 